\title{
Being low prepares for being neglected: Verticality affects expectancy of social participation
}

\author{
Michael Niedeggen $^{1} \cdot$ Rudolf Kerschreiter $^{1} \cdot$ Diane Hirte $^{1} \cdot$ Sarah Weschke $^{1}$
}

Published online: 1 July 2016

(C) Psychonomic Society, Inc. 2016

\begin{abstract}
Previous research suggests that the established link of vertical position and self-assignment of social power affects the processing of social exclusion. We hypothesized that verticality-induced self-assignment of social power moderates the evaluation of exclusion via a change in subjective expectancy of social participation. Following this idea, a superior position-associated with higher power-was supposed to increase the sensitivity for a transition to social exclusion. The transition was simulated in a virtual ball tossing game (cyberball): an inclusionary block was followed by partial exclusion of the participant. The participants' vertical position relative to the co-players was varied in three experimental groups (superior vs. even vs. inferior). From inclusion to partial exclusion, we observed an increase of an event-related brain potential related to the violation of subjective expectancy (P3), and participants reported a corresponding increase in threat to social needs and negative mood. For participants at inferior position exclusionary effects on both, P3 and need threat, were less pronounced as compared to participants at even or superior position. These results indicate that verticality impacts basic cognitive processes of subjective expectancy formation. An inferior position already provides a bias for the loss of social power, and the transition to social exclusion is less unexpected.
\end{abstract}

Electronic supplementary material The online version of this article (doi:10.3758/s13423-016-1115-5) contains supplementary material, which is available to authorized users.

Michael Niedeggen

michael.niedeggen@fu-berlin.de

1 Department of Education and Psychology, Freie Universität Berlin, Habelschwerdter Allee 45, D-14195 Berlin, Germany
Keywords Social cognition $\cdot$ Evoked potentials $\cdot$ Cyberball . Expectancy $\cdot$ Verticality

\section{Introduction}

The social power of an individual is commonly visualized by the vertical position within a hierarchy. "High" indicates control over others, "low" a subordinate status (Fiske, 1992). Vertical position, however, does not only serve as a metaphor but is a perceptual symbol for power affecting our social judgments inevitably. For example, the vertical difference between two group names printed on a screen affected the identification of the powerful one (Schubert, 2005).

Because power refers to the disproportionate control over other individuals' outcomes (Fast \& Chen, 2009), power should affect the processing of social exclusion. According to Williams (Williams, 2007; Zadro, Williams, \& Richardson, 2004), social exclusion threatens human needs (belonging, self-esteem, control, and meaningful existence) and elicits negative mood. This response is assumed to rely on the automatic activation of a neural alarm system detecting the slightest hints of ostracism. The process is reliably elicited in the cyberball paradigm. The participant is represented by an avatar on a computer screen, and two other avatars putatively represent human co-players connected via internet. In inclusionary blocks, the ball is passed to the participant approximately a third of the time, whereas the two assumed coplayers passed the ball back and forth in exclusionary blocks. The latter threatens the social needs measured in the Need Threat Questionnaire (NTQ, Williams, Cheung, \& Choi, 2000). The sensitivity of the alarm system, and consequently the threat to social needs, can be assumed to be affected by the self-assignment of social power. 
First evidence was provided by Schoel and colleagues (Schoel, Eck, \& Greifeneder, 2014). They noted that the standard setup of the cyberball paradigm (Fig. 1a) considers the spatial distance to the co-players but that the screen position of the participant below both co-players might serve as a perceptual symbol for the lack of social power. Consequently, they flipped the standard setup vertically so that the participant was positioned above both co-players. Participants at superior position responded to exclusion less sensitively and experienced less threat to social control than participants at inferior position. Contrasting this finding, a recent study of interpersonal justice indicated that power heightens the sensitivity for social exclusion in the cyberball paradigm (Sawaoka, Hughes, \& Ambady, 2015).
The more general question is how the verticality-power link affects the processing of social exclusion. We suppose that an important process in the evaluation of social participation is subjective expectancy, which refers to cognitions (or beliefs) regarding contingencies and frequencies of relevant social events. Theoretical models on social exclusion already suggest that only actions that are more exclusionary than expected trigger the social exclusion alarm system (Kerr \& Levine, 2008). At superior vertical position, the selfassignment of social power is increased (Schubert, 2005) and leads to a sense of entitlement (De Cremer \& Van Dijk, 2005). A corresponding increase in expectancy of social participation also should increase the sensitivity to social exclusion.
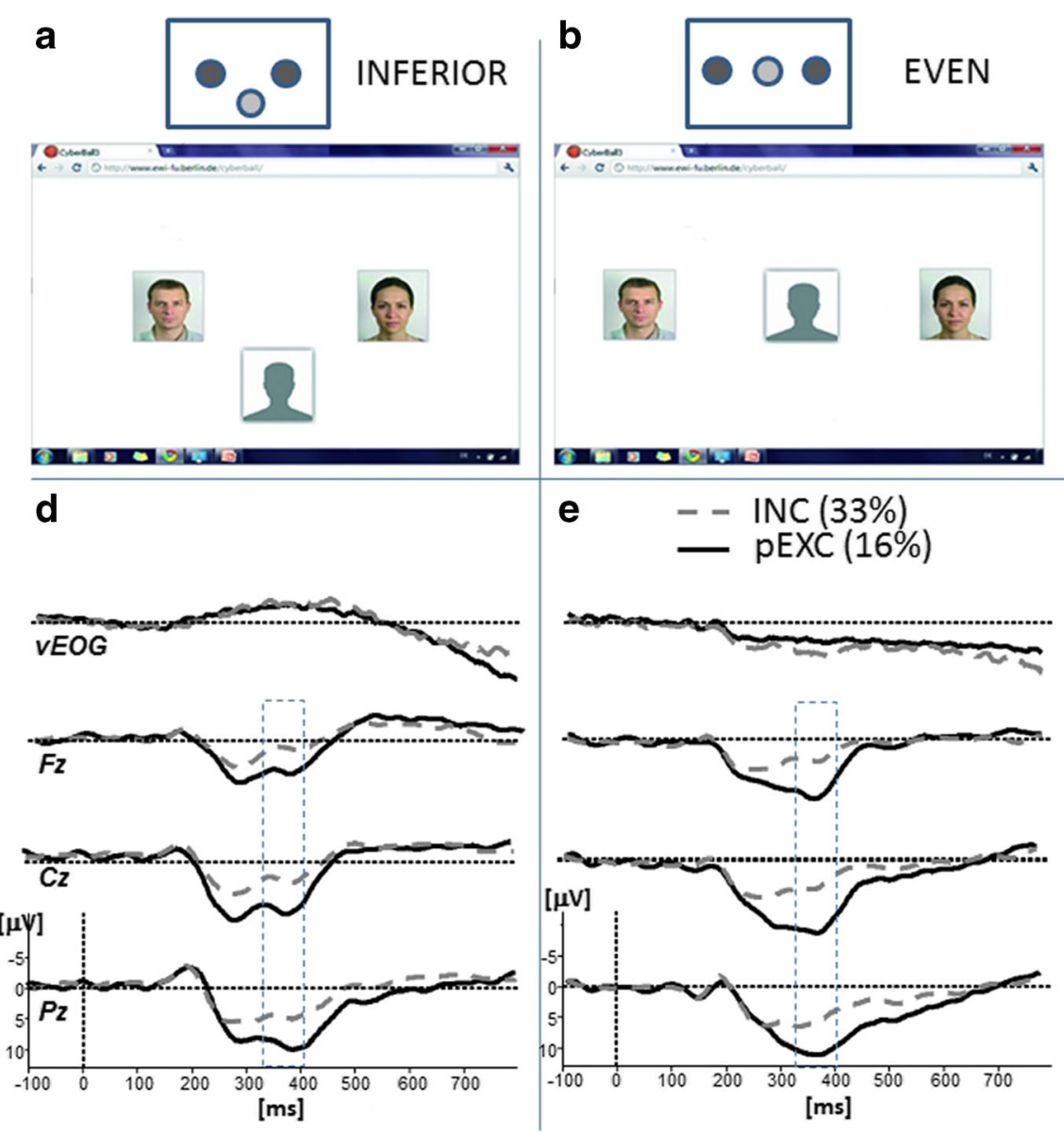

\section{r}

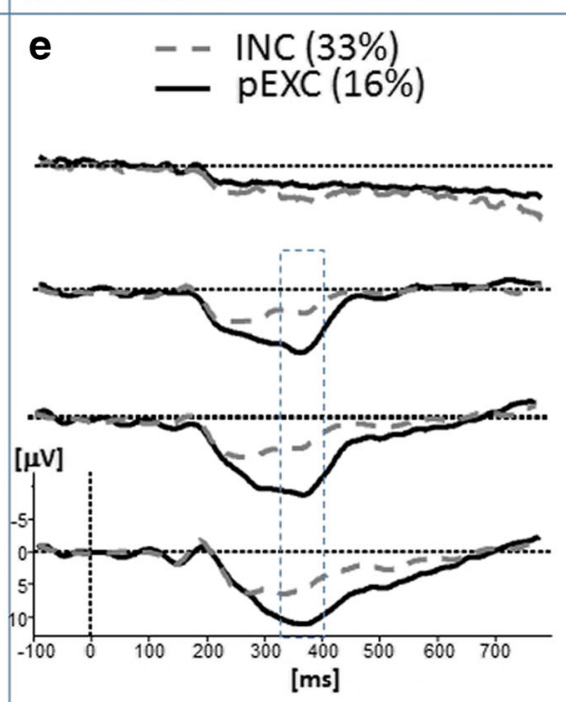

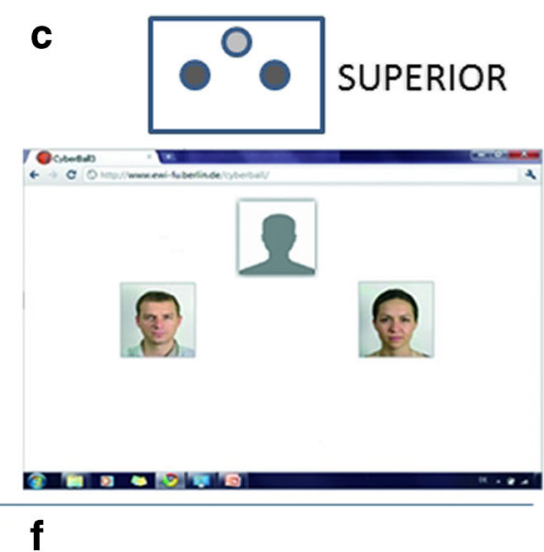

f

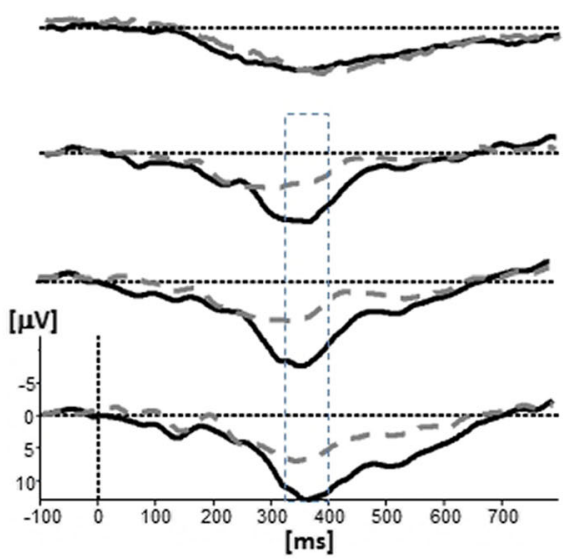

Fig. 1 A-C. Display for the three experimental groups "inferior," "even," and "superior," and the corresponding icons. Position of the participant was centered horizontally but systematically varied verticallydepending on group assignment. To indicate "ball possession," the ball appeared slightly below the position of the avatar on the screen. If it appeared at the position of the participants' avatar, the subject was required to move the ball to a co-player by pressing a corresponding button on a keyboard. The ball vanished for $500 \mathrm{~ms}$ and was consequently presented on the selected co-player's position. If the ball appeared on the position of one of the co-players' avatar, where it remained for 400-1400 ms, vanished for $500 \mathrm{~ms}$, and appeared on the position of the participants' or other co-players' avatar. Please note that the pictures of the co-players were not real photos, but morphs derived from different persons' photos. D-F. Grand-averaged midline ERPs (negativity up) and vertical eye movement signals (vEOG) elicited by the event "ball reception" of the participant at three central electrode positions ( $\mathrm{Fz}, \mathrm{Cz}$, and $\mathrm{Pz}$ ). For each experimental group, the superimposed traces for the blocks "inclusion" (dashed lines) and "partial exclusion" (solid lines) are presented. The analysis focused on the late part of the positive ERP component (P3, 320-400 ms) 
To enable a better understanding of the role of expectancy in the processing of social exclusion, we tracked the adjustment in expectancy online by recording event-related brain potentials (ERPs). As shown previously, the event "ball reception" in the cyberball game triggers an ERP positivity peaking at about $350 \mathrm{~ms}$ (Gutz, Küpper, Renneberg, \& Niedeggen, 2011). Compared with a preceding inclusionary block (ball reception $33 \%$ ), partial exclusion (ball reception $16 \%$ ) enhanced this positivity (Weschke \& Niedeggen, 2013), whereas the transition to overinclusion (ball reception $46 \%$ ) reduced it (Niedeggen, Sarauli, Cacciola, \& Weschke, 2014). This ERP effect-also shared by the well-established P3 component elicited in the oddball paradigm (Donchin, 1981; Polich, 2007) — was related to a corresponding increase (partial exclusion) or decrease (overinclusion) of threat to social needs measured retrospectively in the NTQ. Recent findings suggest that the $\mathrm{P} 3$ effect in cyberball does not merely reflect the reduced probability of ball reception but is linked to a readjustment of subjective expectancy (Weschke \& Niedeggen, 2015): If the transition to partial exclusion (33\% to $16 \%$ ball reception) was associated with an increase in the number of virtual co-players ( 2 to 5 co-players), expectancy for participation was not violated, and neither an increase in P3 amplitude nor in threat to social needs was observed.

In the current study, we explored whether the verticality of position in the cyberball game moderates the aforementioned effects of transition to partial exclusion. Following an expectancy approach, we predicted that participants at superior position are more sensitive to a transfer to social exclusion than participants at inferior position. At superior position, the onset of partial exclusion is less expected. Therefore, the readjustment of expectancy will reflect itself in a larger P3 amplitude and a stronger threat to social needs (Sawaoka et al., 2015). To determine whether the supposed effect of verticality is related to an enhanced sensitivity of the superior group, or to a reduced sensitivity of the inferior group, we added a third experimental group in which all players were positioned on even vertical level.

\section{Method}

\section{Participants}

The procedure was approved by the local ethics committee. All participants gave their written consent for participating according to the Declaration of Helsinki. Eleven of 53 participants had to be excluded because the averaged ERP relied on less than 15 single sweeps at least in one experimental condition. In this case, data reliability was rated as low and the participant was excluded from analysis.

The remaining 42 participants had self-reportedly no history of psychiatric or neurological disorders. Participants were assigned to one of the three experimental groups (inferior $n=$ 14,7 females, mean age $=24.1$ years; even $n=14,8$ females, mean age $=22.3$ years; superior $n=14,7$ females, mean age $=$ 21.9 years). Based on the results of a previous study using a similar experimental design ( 3 independent groups $\mathrm{x} 2$ inclusion conditions (Gutz, Renneberg, Roepke, \& Niedeggen, 2015)), we expected a medium-sized interaction effect. A power analysis using G*Power (Erdfelder, Faul, \& Buchner, 1996) indicated that a total sample of 39 participants would be needed to detect medium effects $\left(\eta_{\mathrm{p}}{ }^{2}=0.10\right.$, adjusted to the taxonomy of (Cohen, 1988)) with a $95 \%$ power using a $F$ test with alpha at 0.05 . Because a cover story was required to induce the experimental effect, participants were informed about the experimental technique and aims of the study afterwards.

\section{Task and design}

The experimental setup (cyberball game including the instructions) was programmed in MATLAB (R2012a, The MathWorks, Inc.) and has been described in detail elsewhere (Niedeggen et al., 2014). The position of the photos of two putatively connected co-players was centered with respect to verticality. Position of the avatar of the participant was centered horizontally, but its vertical position depended on the group assignment: In the group "inferior," it was positioned below the photos corresponding to the two co-players, in the group "superior" the avatar was above, and in the group "even" all players were positioned on even vertical level (Fig. 1b). In all conditions, the distance to the photos of the co-players was comparable $\left(3^{\circ}\right)$.

All participants went through two blocks (each 200 throws) of the cyberball game. In the inclusionary block (INC, proportionate ball reception), the participant received the ball in about one third of all ball throws (33\%); in the partial exclusion block ( $p E X C$, disproportionate ball reception), the probability of getting the ball was reduced to $16 \%$. Immediately following the second block, participants were told to retrospectively fill out questionnaires (NTQ, negative mood scale, estimated frequency of ball reception), referring to the first (INC), and the second block (pEXC). Completing the first set of questionnaires immediately following the first block might sensitize the participant and shift attention to the degree of participation in the second block.

\section{EEG Recording}

EEG data were recorded from eight active $\mathrm{Ag} / \mathrm{AgCl}$ electrodes positioned at $\mathrm{Fp} 1, \mathrm{Fp} 2, \mathrm{AFz}, \mathrm{F} 3, \mathrm{Fz}, \mathrm{F} 4, \mathrm{Cz}$, and Pz. The analysis was focused on the midline electrodes (Fz, Cz, Pz), which were already identified to be highly sensitive to record the components of interest (Niedeggen et al., 2014). Active electrodes (impedance $<5 \mathrm{k} \Omega$ ) were 
referenced to linked earlobes. Vertical and horizontal electrooculogram (EOG) were recorded to control for ocular artifacts. Biosignals were recorded continuously with EEG-8 amplifiers (Contact precision instruments, Cambridge, UK) at $500 \mathrm{~Hz}$. Offline, EEG data were analyzed using Brain Vision Analyzer (Version 1.05, Brain Products GmbH, Gilching, Germany). EEG was segmented according to the onset of ball reception $(-100$ to $700 \mathrm{~ms}$ epoch length), filtered $(0.3-30 \mathrm{~Hz}, 24 \mathrm{~dB} /$ Oct), and baseline corrected (-100 to $0 \mathrm{~ms}$ ). Single EEG sweeps containing muscular or ocular artifacts were excluded from analysis, as well as EEG trials with high alpha activity $(>80 \mu \mathrm{V})$. Because there were more segments for ball possession in the condition inclusion (INC) by definition, the number of EEG segments was randomly chosen to adjust it to the number of segments obtained in the condition partial exclusion $(p E X C)$.

\section{Data analysis}

EEG data Averaged ERPs were separately analysed for the between factor "position" (inferior, even, superior) and the within factors "probability" (INC, pEXC), ball reception (self, other), and electrode position ( $\mathrm{Fz}, \mathrm{Cz}, \mathrm{Pz})$. The results section will focus on the "self" event (ball reception of the participant), which probed the status of subjective expectancysupposed to be modulated by verticality. ERPs to the event 'other' (ball reception of the co-players) were not significantly modulated by the factor "verticality."

The P3 effect extended from 240 to $400 \mathrm{~ms}$. Two segments were defined for analysis. The early segment was defined by the maximum of the P3 complex at frontal sites $(280 \mathrm{~ms})$ and extended from 240 to $320 \mathrm{~ms}$. Here, the effect of probability was already significantly expressed. The later segment was based on the peak of the P3 at central leads $(360 \mathrm{~ms})$ and extended from 320 to $400 \mathrm{~ms}$. Since effects of position were restricted to the later segment, description of results will focus on this time range. Mean amplitudes were exported and analyzed using SPSS (version 22, IBM). Repeated measures ANOVAs were calculated, including the between-subject factor position and the within-subject factors probability and electrode position.

To control for an effect of vertical eye movements - driven by the change of the ball's vertical position - we also extracted the mean level of the vEOG signal in the time segment of interest (320-400 ms). As for the ERP data, effects of position and probability were analyzed running a repeated measure ANOVA.

Questionnaire data For each participant, data of the NTQ and additional questions (negative mood, estimated frequency of ball reception) were entered into SPSS (version 22, IBM) and scales were computed. The single NTQ scales (belonging, self-esteem, control, meaningful existence) and negative mood were analyzed running $3 \times 2$ ANOVAs, including the between-subject factor position and the within-subject factor probability. The NTQ scales were analyzed independently because they refer to different psychological constructs (Williams \& Nida, 2011) and are correspondingly affected selectively by experimental manipulation (Schoel et al., 2014). As for the ERP data, degrees of freedom and $p$ values were corrected according to Greenhouse-Geisser, if indicated by a Mauchly's test of sphericity, and corrected $p$ values will be reported. In case of significant interactions, post-hoc comparisons were performed.

\section{Results}

Questionnaire data are summarized in Table 1, and the results of the corresponding analyses of variance (ANOVA) are presented in Table 2. Analysis of the estimated frequency of ball reception (Fig. 2a) showed that the experimental manipulation of social participation was reliably perceived in all groups: a reduced ball reception in the exclusionary block was consistently reported. The significant main effect of the factor probability did not interact with the between-factor position. Ball reception in both blocks was slightly underestimated in the group superior, but the ANOVA indicates that the difference failed to reach significance.

For all single NTQ scales, social needs were found to be significantly reduced following partial exclusion. Separate ANOVAs confirmed an increase of threat to social needs in the exclusion block, whereas no significant effect of the players' position was observed. An interaction of probability and position was significantly expressed for two NTQ scales: The reduction of selfesteem and control induced by the transition to partial exclusion was more pronounced for the vertical positions even and superior compared with inferior. Therefore, for both scales, we performed post-hoc comparisons between the groups, and the exclusionary effect $(\Delta$ (pEXC-INC)) served as dependent variable (Table 2). For self-esteem, significant differences between the groups inferior and even, as well as inferior and superior were found. However, no reliable difference was found for the comparison of the groups even vs. superior. The same pattern of results was observed for the scale control.

Negative mood was significantly enhanced by a transition to partial exclusion, and the overall level was affected by position. As indicated by Fig. 2c, this main effect was primarily due to an strong enhancement of negative mood in the groups even and superior in partial exclusion. This selective effect of transition was confirmed by a significant interaction of the experimental factors probability and position. Post-hoc comparison confirmed that the exclusion effect on negative 
Table 1 Means for the questionnaire and ERP data, separated for group assignment (verticality: inferior vs. even vs. superior) and cyberball blocks (block 1: inclusion [INC], block 2: partial exclusion [pEXC])

\begin{tabular}{|c|c|c|c|c|c|c|}
\hline \multirow[t]{2}{*}{ Position } & \multicolumn{2}{|l|}{ Inferior } & \multicolumn{2}{|l|}{ Even } & \multicolumn{2}{|l|}{ Superior } \\
\hline & INC & $\mathrm{pEXC}$ & INC & $\mathrm{pEXC}$ & INC & $\mathrm{pEXC}$ \\
\hline Estimated ball reception [\%] & $\begin{array}{l}36.3 \\
{[31.5,41.1]}\end{array}$ & $\begin{array}{l}15.2 \\
{[12.7,17.8]}\end{array}$ & $\begin{array}{l}34.3 \\
{[29.5,39.1]}\end{array}$ & $\begin{array}{l}12.5 \\
{[9.9,15.1]}\end{array}$ & $\begin{array}{l}30.6 \\
{[25.5,41.1]}\end{array}$ & $\begin{array}{l}12.1 \\
{[9.6,14.7]}\end{array}$ \\
\hline NTQ: belonging & $\begin{array}{l}4.12 \\
{[3.76,4.48]}\end{array}$ & $\begin{array}{l}2.95 \\
{[2.46,3.45]}\end{array}$ & $\begin{array}{l}4.00 \\
{[3.64-4.36]}\end{array}$ & $\begin{array}{l}2.14 \\
{[1.65,2.64]}\end{array}$ & $\begin{array}{l}4.05 \\
{[3.69,4.41]}\end{array}$ & $\begin{array}{l}2.29 \\
{[1.79,2.78]}\end{array}$ \\
\hline NTQ: self-esteem & $\begin{array}{l}3.50 \\
{[3.18,3.88]}\end{array}$ & $\begin{array}{l}3.19 \\
{[2.79,3.59]}\end{array}$ & $\begin{array}{l}3.76 \\
{[3.38,4.14]}\end{array}$ & $\begin{array}{l}2.19 \\
{[1.79,2.59]}\end{array}$ & $\begin{array}{l}3.83 \\
{[3.45,4.22]}\end{array}$ & $\begin{array}{l}2.43 \\
{[2.03,2.83]}\end{array}$ \\
\hline NTQ: meaningful existence & $\begin{array}{l}4.62 \\
{[4.24,4.99]}\end{array}$ & $\begin{array}{l}3.81 \\
{[3.22,4.40]}\end{array}$ & $\begin{array}{l}4.23 \\
{[3.86,4.61]}\end{array}$ & $\begin{array}{l}2.88 \\
{[2.29,3.48]}\end{array}$ & $\begin{array}{l}4.33 \\
{[3.96,4.71]}\end{array}$ & $\begin{array}{l}2.81 \\
{[2.22,3.40]}\end{array}$ \\
\hline NTQ: control & $\begin{array}{l}2.31 \\
{[1.90,2.72]}\end{array}$ & $\begin{array}{l}1.88 \\
{[1.56,2.20]}\end{array}$ & $\begin{array}{l}2.64 \\
{[2.64,1.31]}\end{array}$ & $\begin{array}{l}1.31 \\
{[0.99,1.63]}\end{array}$ & $\begin{array}{l}2.67 \\
{[2.26,3.07]}\end{array}$ & $\begin{array}{l}1.59 \\
{[1.28,1.91]}\end{array}$ \\
\hline Negative mood & $\begin{array}{l}9.46 \\
{[8.79,10.14]}\end{array}$ & $\begin{array}{l}10.57 \\
{[9.73,11.41]}\end{array}$ & $\begin{array}{l}10.28 \\
{[9.61,12.16]}\end{array}$ & $\begin{array}{l}13.00 \\
{[12.16,13.84]}\end{array}$ & $\begin{array}{l}9.53 \\
{[8.86,10.21]}\end{array}$ & $\begin{array}{l}12.57 \\
{[1.73,13.41]}\end{array}$ \\
\hline P3 amplitude & $\begin{array}{l}3.54 \\
{[1.87,4.65]}\end{array}$ & $\begin{array}{l}7.01 \\
{[4.65,9.37]}\end{array}$ & $\begin{array}{l}3.69 \\
{[2.02,5.36]}\end{array}$ & $\begin{array}{l}10.26 \\
{[7.90,12.62]}\end{array}$ & $\begin{array}{l}5.75 \\
{[4.08,7.42]}\end{array}$ & $\begin{array}{l}12.18 \\
{[9.82,14.54]}\end{array}$ \\
\hline
\end{tabular}

Upper and lower limits of confidence intervals $(95 \%)$ are provided in brackets

mood $(\Delta(\mathrm{pEXC}-\mathrm{INC}))$ was significantly less expressed for the group inferior compared with the other experimental groups.

The grand-averaged ERPs (Fig. 1d-f) indicate that the effect of partial exclusion was reflected in a more positive going ERP wave (P3). In the time window explored (320-400 ms), the amplitude was larger at central and parietal compared with the frontal lead (electrode: $F(2,78)=21.70, p<0.001, \eta_{\mathrm{p}}{ }^{2}=$ 0.36 ). The effects of the experimental factors condition and position, reported in the following, were not modulated by electrode position.

Confirming previous ERP results (Gutz et al., 2011; Weschke \& Niedeggen, 2013), the effect of probability on P3 amplitude was significantly expressed. In each experimental group (inferior, even, and superior), a reliable increase of amplitude was induced by the transition to partial exclusion. The overall level of the P3 amplitude was different between the groups. This group difference was due to a different responsivity to the transition to partial exclusion. As indicated by the significant interaction of the factors probability and position, the increase in $\mathrm{P} 3$ amplitude was less expressed in the inferior group compared with the even and superior groups (Fig. 2d). Post-hoc comparisons confirmed that the ERP probability effect $(\Delta$ (pEXC-INC) ) was selectively reduced in the group inferior compared with the groups even and superior, respectively. No difference was observed between the groups even and superior (Table 2).

The P3 effect $(\Delta$ (pEXC-INC) $)$ averaged for the midline electrodes was found to be significantly correlated with the
NTQ effect averaged for the four scales $(r=-0.451, p=$ $0.003)$, and with the corresponding change in negative mood $(r=0.470, p=0.002){ }^{1}$

Visual inspection of Fig. 1d-f also revealed that the change of the vertical ball position was associated with a corresponding shift in the vEOG. Within the time window of interest (320-400 ms), the amplitude of the vEOG signal therefore depended on group assignment (position: $F(2,39)=10,252$, $\left.p=0.001, \eta_{\mathrm{p}}^{2}=0.35\right)$. However, the vertical shift was not modulated by the experimental manipulation of probability, $F(1,39)=0.468, p=0.498, \eta_{\mathrm{p}}{ }^{2}=0.01$. Most importantly, the position effect on the vEOG was not affected by probability, $F(2,39)=0.637, p=0.535, \eta_{\mathrm{p}}{ }^{2}=0.03$.

\section{Discussion}

The present research confirms that the transition from inclusion to partial exclusion in the cyberball game elicits highly reliable effects in questionnaire and ERP data. All social needs covered in the NTQ (belonging, meaningful existence, control, and self-esteem) were threatened, and negative mood was enhanced. Correspondingly, the late P3 component was increased. Moreover, the expression of the transition effect-on questionnaire as well as on ERP level — was affected by the verticality of the player's

\footnotetext{
${ }^{1}$ A more detailed description of correlations is provided in the supplementary material.
} 
Table 2 Results of the inference statistics (ANOVA) for the questionnaire and ERP data

EXPERIMENTAL FACTORS

Position

$F(2,39)=3.21$

$p=0.051, \eta_{\mathrm{p}}^{2}=0.14$

$F(2,39)=2.48$

$p=0.096, \eta_{\mathrm{p}}^{2}=0.11$

TQ: belong

NTQ: self-esteem

$F(2,39)=1.91$ $p=0.161, \eta_{\mathrm{p}}^{2}=0.09$

NTQ: meaningful existence

NTQ: control

Negative mood

$F(2,39)=3.17$ $p=0.053, \eta_{\mathrm{p}}^{2}=0.15$

$F(2,39)=0.35$ $p=0.706, \eta_{\mathrm{p}}{ }^{2}=0.02$

$F(2,39)=8.98$

$p=0.001, \eta_{\mathrm{p}}{ }^{2}=0.32$

$F(2,39)=4.22$

$p=0.022, \eta_{\mathrm{p}}{ }^{2}=0.18$

$F(1,39)=149.19$

$p<0.001, \eta_{\mathrm{p}}^{2}=0.79$

$F(1,39)=86.88$

$p<0.001, \eta_{\mathrm{p}}^{2}=0.69$

$F(1,39)=46.69$

$p<0.001, \eta_{\mathrm{p}}^{2}=0.55$

$F(1,39)=46.69$

$p<0.001, \eta_{\mathrm{p}}^{2}=0.54$

$F(1,39)=49.20$

$p<0.001, \eta_{\mathrm{p}}^{2}=0.56$

$F(1,39)=58.74$

$p<0.001, \eta_{\mathrm{p}}{ }^{2}=0.60$

$F(1,39)=106.12$

$p<0.001, \eta_{\mathrm{p}}^{2}=0.73$

P3 amplitude

\section{POST-HOC COMPARISONS}

Effect of position on transition effect: $\Delta(I N C-p E X C)$

\begin{tabular}{lll}
\hline $\begin{array}{ll}\text { Inferior vs. } \\
\text { even }\end{array}$ & $\begin{array}{l}\text { Inferior vs. } \\
\text { superior }\end{array}$ & $\begin{array}{l}\text { Even vs. } \\
\text { superior }\end{array}$
\end{tabular}

$0.18 \quad p<0.001, \eta_{\mathrm{p}}{ }^{2}=0.73 \quad p=0.037, \eta_{\mathrm{p}}{ }^{2}=0.16$

$\begin{array}{lll}\text { n.i. } & \text { n.i. } & \text { n.i. } \\ \text { n.i. } & \text { n.i. } & \text { n.i. } \\ & & \\ F(1,26)=12.78 & F(1,26)=17.17 & F(1,26)=0.21 \\ p<0.001, \eta_{\mathrm{p}}{ }^{2}=0.33 & p<0.001, \eta_{\mathrm{p}}{ }^{2}=0.40 & p=0.651, \eta_{\mathrm{p}}{ }^{2}=0.01 \\ \text { n.i. } & \text { n.i. } & \text { n.i. } \\ & & \\ F(1,26)=11.70 & F(1,26)=5.76 & F(1,26)=0.13 \\ p=0.002, \eta_{\mathrm{p}}{ }^{2}=0.31 & p=0.024, \eta_{\mathrm{p}}{ }^{2}=0.18 & p=0.717, \eta_{\mathrm{p}}{ }^{2}=0.005 \\ F(1,26)=12.12 & F(1,26)=14.83 & F(1,26)=0.69 \\ p=0.002, \eta_{\mathrm{p}}{ }^{2}=0.32 & p<0.001, \eta_{\mathrm{p}}{ }^{2}=0.36 ; & p=0.685, \eta_{\mathrm{p}}{ }^{2}=0.006 \\ F(1,26)=7.62 & F(1,26)=5.02 & F(1,26)=0.009 \\ p=0.010, \eta_{\mathrm{p}}{ }^{2}=0.23 & p=0.034, \eta_{\mathrm{p}}{ }^{2}=0.16 & p=0.927, \eta_{\mathrm{p}}{ }^{2}=0.000\end{array}$

In case of an interaction of the experimental factors "position" and "probability," results of the post-hoc comparisons are provided. The effect of transition $(\triangle(\mathrm{INC}-\mathrm{pEXC}))$ was compared pairwise for the three experimental groups

n.i. = not indicated by an interaction "position" $\mathrm{x}$ "probability")

position. Compared with superior or even position, for players at the inferior position control and self-esteem were less threatened, negative mood was less enhanced, and the increase of the P3 amplitude signaling expectancy violation was less expressed. Two main conclusions can be drawn from these results.

First, the seminal model of Williams (2007) suggests that the activation of a preattentive neural alarm system triggers social pain and determines the threat of social needs. We showed that the participants' evaluation of a transition from inclusion to exclusion also depends on subjective expectancy of participation - as already proposed in a theoretical model of social exclusion by Kerr \& Levine (2008). The violation of expectancy is reflected in the change in P3 amplitude (Polich \& Bondurant, 1997; Stadler, Klimesch, Pouthas, \& Ragot, 2006) and accompanies the NTQ effects (Weschke \& Niedeggen, 2015). A similar relation of expectancy violation and social rejection has been supposed in a neuroimaging study focusing on the activity in the anterior cingulate cortex (Somerville, Heatherton, \& Kelley, 2006). Furthermore, the expectancy violation account of social exclusion we suggested here can be integrated in a unified motivational account of inconsistency compensation recently proposed (Proulx, Inzlicht, \& Harmon-Jones, 2012). This latter account assumes that inconsistencies, such as violation of expectations, activate common neurocognitive structures triggering an aversive arousal. In our data set, the corresponding link probably is reflected in the correlation of the $\mathrm{P} 3$ effect and change in negative mood.
Second, our results are in agreement with the idea that verticality and social power are closely linked. More importantly, we show that vertical position can bias the subjective expectancy of social participation. However, this bias in the expectation of social participation was only activated by a transition to social exclusion. As depicted in Fig. 2, group differences in ERP and questionnaire data were not significantly expressed in the initial inclusionary condition, but the onset of partial exclusion was processed differently: At inferior position, exclusionary events are apparently more expected, and a readjustment process is less activated. This is indicated by a smaller change in P3 amplitude from inclusion to exclusion and retrospectively by a lower threat of social needs.

Our data further indicate that the bias in the expectation of social participation is exclusively expressed at inferior position, whereas a transfer to social exclusion has comparable effect at even and superior position. ${ }^{2}$ One might speculate that this pattern of results indicates a categorical rather than linear transfer of vertical position to the self-assignment of social power (Slepian, Masicampo, \& Ambady, 2015).

\footnotetext{
$\overline{2}$ The effect on the self-assignment of power can be illustrated in the NTQ item "I felt superior to my co-players": Although comparable in the inclusion condition (mean rating and standard deviation: inferior 1.99 [0.89], even 2.36 [1.21], superior 2.21 [1.12]), partial exclusion affected only the rating of the groups even (rating: 1.50 [1.09], $t(14)=3.12, p=$ 0.008 ) and slightly the group superior (rating: $1.71[0.91], t(14)=2.00, p$ $=0.060)$. Rating of the inferior group was clearly not affected $(1.95$ [0.98], $t(14)=0.05, p=0.92$ ).
} 


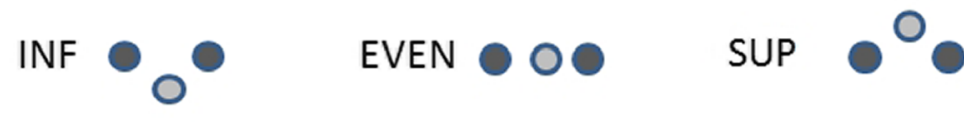

a

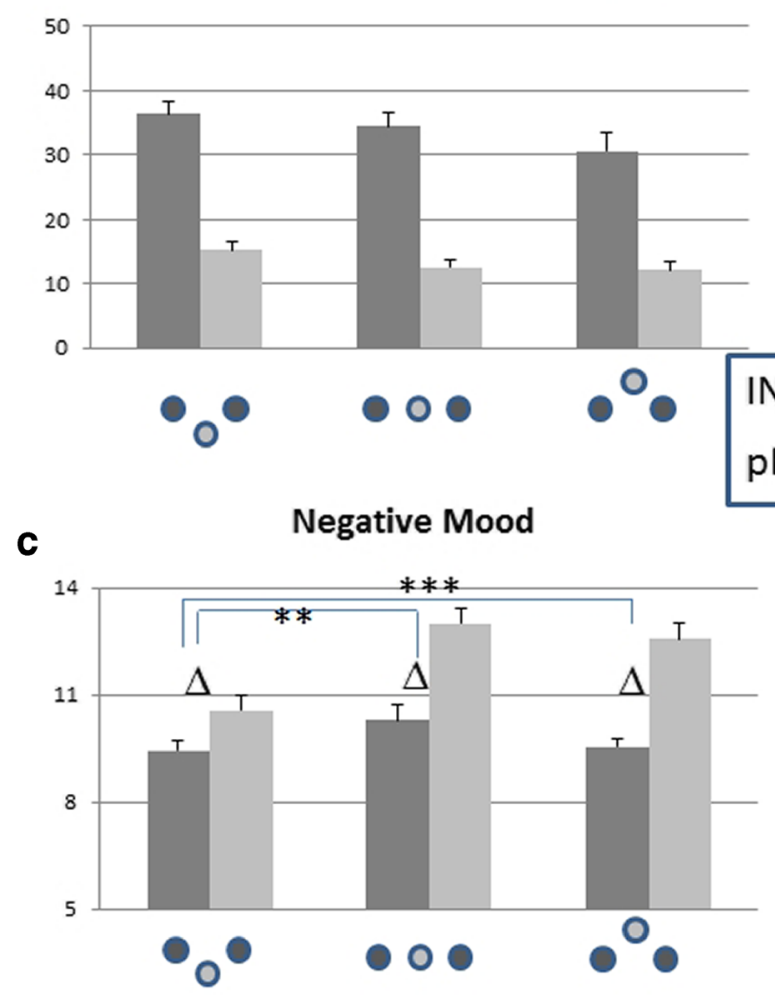

b

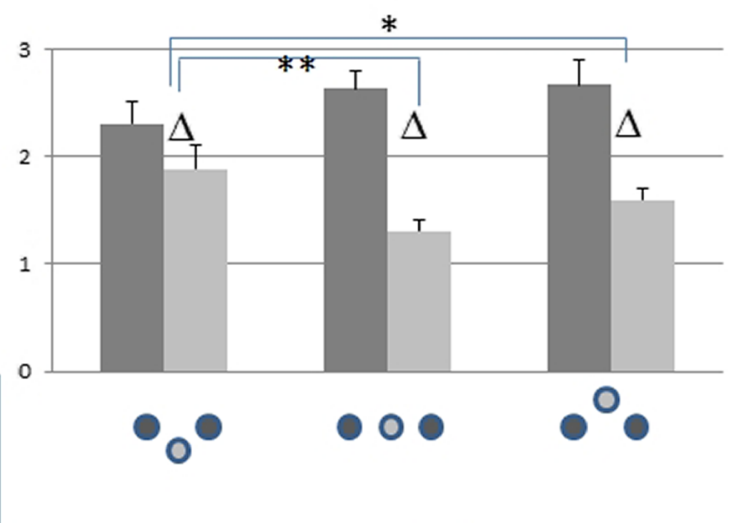

Late P3 $[\mu \mathrm{V}]$

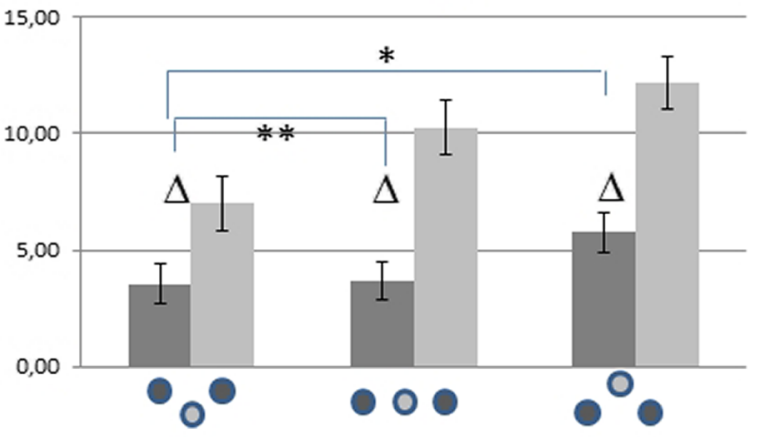

Fig. 2 Mean questionnaire and ERP data separated for the two blocks (inclusion [INC] vs. partial exclusion [pEXC]) and experimental groups (inferior vs. even vs. superior). Error bars refer to standard errors of the mean. Results of the post-hoc comparisons of the effect of exclusion $(\Delta(\mathrm{pEXC}-\mathrm{INC}))$ are indicated $(* p<0.05, * * p<0.01, * * * p<0.001)$. A. The estimated ball reception signaled that participants correctly

As mentioned earlier, previous studies provided different results on the direction of the effect of selfassigned power on the sensitivity for social exclusion (Sawaoka et al., 2015; Schoel et al., 2014). The previous cyberball study using independent groups in the inclusion and exclusion conditions suggests that participants at superior position are less sensitive to the threat of social control (Schoel et al., 2014). Using a withinsubject baseline (inclusion), we focused on the violation of expectations triggered by the transition to partial exclusion, and found sensitivity to be decreased at inferior position. The contradictory results are probably due to the different experimental setup: If short runs with an immediate onset of exclusion are used (Schoel et al., 2014), deviations from expectations are more difficult noticed the change in probability. B. Partial exclusion decreased belief in social control. This effect was less pronounced in the inferior group. $\mathbf{C}$. Partial exclusion increased negative mood. Again, this effect was less pronounced in the inferior group. D. Partial exclusion increased the amplitude of the P3 complex. Again, this increase was less pronounced in the inferior group to estimate. The impact of a baseline condition on the adjustment of expectation remains to be explored in future research.

The present research supports the notion that the verticality of position affects the subjective expectation of social participation and, therefore, the evaluation of the transition from inclusion to exclusion. The deviation in expectancy eliciting a threat to social needs (Kerr \& Levine, 2008) is less expressed at inferior position. A promising avenue for future research would be to clarify whether the effect of the verticality-power link on subjective expectancy also applies for research questions beyond the field of ostracism, such as leadership effects in organizational psychology (e.g., "Your highness", Schubert, 2005). 


\section{References}

Cohen, J. (1988). Statistical power analysis for the behavioral sciences (2nd ed.). Hillsdale, N.J.: L. Erlbaum Associates.

De Cremer, D., \& Van Dijk, E. (2005). When and why leaders put themselves first: Leader behaviour in resource allocations as a function of feeling entitled. European Journal of Social Psychology, 35(4), 553-563. doi:10.1002/Ejsp.260

Donchin, E. (1981). Presidential address, 1980. Surprise!...Surprise? Psychophysiology, 18(5), 493-513.

Erdfelder, E., Faul, F., \& Buchner, A. (1996). Gpower: A general power analysis program. Behavior Research Methods Instruments and Computers, 28, 1-11.

Fast, N. J., \& Chen, S. (2009). When the boss feels inadequate: power, incompetence, and aggression. Psychological Science, 20(11), 1406-1413. doi:10.1111/j.1467-9280.2009.02452.x

Fiske, A. P. (1992). The 4 Elementary Forms of Sociality - Framework for a Unified Theory of Social-Relations. Psychological Review, 99(4), 689-723. doi:10.1037//0033-295x.99.4.689

Gutz, L., Küpper, C., Renneberg, B., \& Niedeggen, M. (2011). Processing social participation: an event-related brain potential study. Neuroreport, 22(9), 453-458. doi:10.1097/Wnr.0b013 e3283476b67

Gutz, L., Renneberg, B., Roepke, S., \& Niedeggen, M. (2015). Neural Processing of Social Participation in Borderline Personality Disorder and Social Anxiety Disorder. Journal of Abnormal Psychology. doi:10.1037/a0038614

Kerr, N. L., \& Levine, J. M. (2008). The detection of social exclusion: Evolution and beyond. Group Dynamics-Theory Research and Practice, 12(1), 39-52. doi:10.1037/1089-2699.12.1.39

Niedeggen, M., Sarauli, N., Cacciola, S., \& Weschke, S. (2014). Are there benefits of social overinclusion? Behavioral and ERP effects in the Cyberball paradigm. Frontiers in Human Neuroscience, 8, 935. doi:10.3389/fnhum.2014.00935

Polich, J. (2007). Updating P300: an integrative theory of P3a and P3b. Clinical Neurophysiology : Official Journal of the International Federation of Clinical Neurophysiology, 118(10), 2128-2148. doi:10.1016/j.clinph.2007.04.019

Polich, J., \& Bondurant, T. (1997). P300 sequence effects, probability, and interstimulus interval. Physiology and Behavior, 61(6), 843849.

Proulx, T., Inzlicht, M., \& Harmon-Jones, E. (2012). Understanding all inconsistency compensation as a palliative response to violated expectations. Trends in Cognitive Sciences, 16(5), 285-291. doi:10.1016/j.tics.2012.04.002

Sawaoka, T., Hughes, B. L., \& Ambady, N. (2015). Power Heightens Sensitivity to Unfairness Against the Self. Personality and Social Psychology Bulletin. doi:10.1177/0146167215588755

Schoel, C., Eck, J., \& Greifeneder, R. (2014). A Matter of Vertical Position: Consequences of Ostracism Differ for Those Above Versus Below Its Perpetrators. Social Psychological and Personality Science, 5(2), 149-157. doi:10.1177 /1948550613488953

Schubert, T. W. (2005). Your highness: vertical positions as perceptual symbols of power. Journal of Personal and Social Psychology, 89(1), 1-21. doi:10.1037/0022-3514.89.1.1

Slepian, M. L., Masicampo, E. J., \& Ambady, N. (2015). Cognition from on high and down low: Verticality and construal level. Journal of Personal and Social Psychology, 108(1), 1-17. doi:10.1037 /a0038265

Somerville, L. H., Heatherton, T. F., \& Kelley, W. M. (2006). Anterior cingulate cortex responds differentially to expectancy violation and social rejection. Nature Neuroscience, 9(8), 1007-1008. doi: $10.1038 / \mathrm{nn} 1728$

Stadler, W., Klimesch, W., Pouthas, V., \& Ragot, R. (2006). Differential effects of the stimulus sequence on CNV and P300. Brain Research, 1123(1), 157-167. doi:10.1016/j.brainres.2006.09.040

Weschke, S., \& Niedeggen, M. (2013). The effect of the physical presence of co-players on perceived ostracism and event-related brain potentials in the cyberball paradigm. PLoS One, 8(8), e71928. doi:10.1371/journal.pone.0071928

Weschke, S., \& Niedeggen, M. (2015). ERP effects and perceived exclusion in the Cyberball paradigm: Correlates of expectancy violation? Brain Research. doi:10.1016/j.brainres.2015.07.038

Williams, K. D. (2007). Ostracism. Annual Review of Psychology, 58, 425-452. doi:10.1146/annurev.psych.58.110405.085641

Williams, K. D., Cheung, C. K., \& Choi, W. (2000). Cyberostracism: effects of being ignored over the Internet. Journal of Personality and Social Psychology, 79(5), 748-762.

Williams, K. D., \& Nida, S. A. (2011). Ostracism: Consequences and Coping. Current Directions in Psychological Science, 20(2), 7175. doi: $10.1177 / 0963721411402480$

Zadro, L., Williams, K. D., \& Richardson, R. (2004). How low can you go? Ostracism by a computer is sufficient to lower self-reported levels of belonging, control, self-esteem, and meaningful existence. Journal of Experimental Social Psychology, 40(4), 560-567. doi:10.1016/j.jesp.2003.11.006 